\title{
Late Effects among Long-Term Survivors of Childhood Acute Leukemia in The Netherlands: A Dutch Childhood Leukemia Study Group Report
}

A. VAN DER DOES-VAN DEN BERG, G. A. M. DE VAAN, J. F. VAN WEERDEN, K. HÄHLEN, M. VAN WEEL-SIPMAN, AND A. J. P. VEERMAN

Dutch Childhood Leukemia Study Group, ${ }^{\prime}$ The Hague, The Netherlands

\begin{abstract}
Late events and side effects are reported in 392 children cured Late events and side effects are reported in 392 children cured
of leukemia. They originated from 1193 consecutively newly diagnosed children between 1972 and 1982, in first continuous complete remission for at least 6 y after diagnosis, and were treated according to Dutch Childhood Leukemia Study Group protocols $(70 \%)$ or institutional protocols $(30 \%)$, all including cranial irradiation for CNS prophylaxis. Data on late events (relapses, death in complete remission, and second malignancies) were collected prospectively after treatment; late side effects were retrospectively collected by a questionnaire, completed by the responsible pediatrician. The event-free survival of the 6-y survivors at $15 \mathrm{y}$ after diagnosis was $92 \%( \pm 2 \%)$. Eight late relapses and nine second malignancies were diagnosed, two children died in first complete remission of late toxicity of treatment, and one child died in a car accident. The most important long-term side effects reported were learning disabilities $(50 \%)$, short stature, obesity, and delayed pubertal development. No increase in the incidence of cardiovascular, pulmonary,
\end{abstract}

urogenital, or gastrointestinal tract diseases or an increased vulnerability of the musculoskeletal system was found. However, prolonged follow-up is necessary to study the full-scale late effects of cytostatic treatment and radiotherapy administered during childhood. (Pediatr Res 38: 802-807, 1995)
Abbreviations
ALL, acute lymphocytic leukemia
ANLL, acute nonlymphocytic leukemia
CCR, continuous first complete remission
DCLSG, Dutch Childhood Leukemia Study Group
EFS, event free survival
HR, high risk
MDS, myelodysplastic syndrome
NHR, nonhigh risk
SDS, SD score
WBC, white blood cell count

Cure is the aim of treatment of children and adolescents with leukemia. In general, children with leukemia who have been in CCR for at least $4 \mathrm{y}$ after cessation of therapy, i.e. $6 \mathrm{y}$ after diagnosis, are considered to be cured (1). Over the past $20 \mathrm{y}$ the cure rate for children with ALL has increased from $5-10 \%$ in the late sixties to $40-50 \%$ in the seventies and $70-80 \%$ in the eighties and early nineties (2). The outlook for children with ANLL is less favorable: only $35-40 \%$ of the patients can expect cure with the current treatment strategies $(3,4)$.

Received November 29, 1994; accepted April 10, 1995)

Manuscript dedicated to Professor H.K.A. Visser in honor of his retirement.

Correspondence and reprint requests: Dr. A. van der Does-van den Berg, Dutch Childhood Leukemia Study Group, P.O.B. 43515, 2504 AM The Hague, The Netherlands.

${ }^{1}$ DCLSG Board Members: W.A. Kamps (chairman), R.S. Weening (secretary), J.A. Rammeloo (treasurer), and H. van den Berg, H.M. van den Berg, J.P.M. Bökkerink, M.C.A. Bruin, S.S.N. de Graaf, K. Hählen, F.A.E. Nabben, I. Risseeuw-Appel, A.Y.N Schouten-van Meeteren, A.J.P. Veerman, E. Th. van't Veer-Korthof, and M. van WeelSipman (members).
It has become increasingly apparent that the treatment to eradicate the leukemia has adverse long-term side effects. These late side effects consist of organ toxicity, disturbances in growth, pubertal and fertility development, psychosocial problems, immunosuppression, and infections. Furthermore, children with cancer are at higher risk for the occurrence of second tumors.

Since 1972 virtually all newly diagnosed children with leukemia in The Netherlands are registered by the DCLSG. The DCLSG provides protocols for treatment and disposes of a Central Office for data management and analysis of treatment results and a Laboratory for confirmation of the diagnosis, immunophenotyping, and classification of the leukemia as well as for follow-up by examination of routine bone marrow and peripheral blood during treatment and after cessation of therapy.

Here we report the results of the DCLSG study on late events and long-term side effects in 392 survivors out of 1193 
consecutively newly diagnosed children with leukemia (age $0-15$ y) in the period 1972-1982, treated with chemotherapy and radiotherapy (cranial irradiation).

\section{METHODS}

Patients. Patients registered by the DCLSG at diagnosis and in first CCR for at least $6 \mathrm{y}$ at January 1, 1988, were eligible for the study.

Treatment. From 1972 to 1975 all ALL patients were treated according to the DCLSG protocols I and II, respectively. After 1975 ALL patients were stratified into two risk groups: ALLNHR constituting $70 \%$ of all ALL patients, and ALL-HR, $30 \%$ of the patients. ALL-NHR was defined as: initial WBC $<50 \times$ $10^{9} / \mathrm{L}$, no mediastinal mass, no initial CNS involvement. All other patients were ALL-HR patients. Children with ALLNHR were treated according to the DCLSG protocols ALL III and ALL V, respectively, children with ALL-HR according to institutional protocols.

Until 1980, children with ANLL were also treated according to institutional protocols, thereafter until 1982 according to the DCLSG protocol ANLL 80. The treatment schemes and results of these DCLSG protocols have been published elsewhere (5-9).

Late events. Registration forms with treatment documentation, data on remission and survival status and, this being the case, on the occurrence of a second tumor, were completed for all patients by the responsible pediatrician regularly during and after cessation of therapy and sent to the Central Office. Blood and bone marrow slides for central examination were also sent to the Central Office.

EFS was defined as the time from diagnosis to relapse, death in remission, or the occurrence of a second tumor. The EFS curve was calculated according to the Kaplan-Meier method (10). Relapse was defined as $\geq 20-25 \%$ blasts in the bone marrow and/or blast cells in the peripheral blood and/or CNS involvement and/or leukemic infiltration elsewhere. Bone marrow and/or CNS relapses as well as second hematologic malignancies had to be confirmed by the DCLSG laboratory.

Late side effects. Data on late side effects were retrospectively collected in $1989-1990$ by a questionnaire to be completed by the responsible pediatrician. This questionnaire contained items concerning organ dysfunction (heart, liver, lungs, CNS, skin, gastrointestinal tract, eyes, musculoskeletal system), severe or chronic diseases (hypertension, endocrine disorders, chronic infections), height, weight, pubertal development and fertility, school performance (the highest level thus far achieved), psychosocial status, employment, and insurances. No specific psychometric tests were performed. As far as possible population-based normal data and figures were used for comparison $(11,12)$.

\section{RESULTS}

\section{Patients}

Three hundred and ninety-two ex-patients were eligible for the study and available for calculation of EFS. The question- naire on late side effects was completed for $273(70 \%)$ expatients. Patient characteristics are summarized in Table 1.

\section{Late Events}

Late events were evaluated as of January 1, 1994. The EFS of the 392 children in longstanding CCR is $92 \%(\mathrm{SE} \pm 2 \%)$ at $15 \mathrm{y}$ after diagnosis (Fig. 1). Eight patients relapsed, in nine patients second malignancies occurred, and three patients died in CCR (Table 2). The estimated cumulative proportion of late relapses and second malignancies $15 \mathrm{y}$ after diagnosis is 3.2 and $3.6 \%$, respectively.

In 5 children the second malignancy developed in the area irradiated for CNS prophylaxis. One of the patients had also been treated with cyclophosphamide. The secondary AML and MDS occurred after treatment with doxorubicin and were associated with abnormalities of chromosome 11 .

Three ex-patients died in CCR: one patient died of preexistent hepatitis which progressed to liver cirrhosis, one patient died after 6 y of coma caused by a cerebral abscess as a consequence of otitis media during cytostatic treatment, and one patient died in a traffic accident. In four patients a histologically benign tumor was diagnosed (Table 2).

Table 1. Patients' characteristics

\begin{tabular}{|c|c|c|}
\hline & $\begin{array}{c}\text { Eligible } \\
(n=392)\end{array}$ & $\begin{array}{l}\text { Questionnaire completed } \\
\qquad(n=273)\end{array}$ \\
\hline \multicolumn{3}{|l|}{ Type of leukemia } \\
\hline ALL & 374 & 263 \\
\hline ANLL & 6 & 4 \\
\hline AUL & 12 & 6 \\
\hline \multicolumn{3}{|l|}{ Year of diagnosis } \\
\hline 1972-1975 & 95 & 57 \\
\hline 1976-1978 & 94 & 73 \\
\hline 1979-1982 & 203 & 143 \\
\hline \multicolumn{3}{|l|}{ Treatment protocol (era) } \\
\hline ALL I (1972-1973) & 3 & 1 \\
\hline ALL II (1973-1975) & 73 & 43 \\
\hline ALL III (1975-1978) & 78 & 56 \\
\hline ALL V (1979-1984) & 173 & 128 \\
\hline ANLL 80 (1980-1982) & 2 & 1 \\
\hline \multicolumn{3}{|l|}{ Institutional } \\
\hline ALL (high risk) & 52 & 38 \\
\hline ANLL & 10 & 5 \\
\hline AUL & 1 & 1 \\
\hline \multicolumn{3}{|l|}{ Sex } \\
\hline Boys & 190 & 136 \\
\hline Girls & 202 & 137 \\
\hline \multicolumn{3}{|l|}{ Age at diagnosis $(\mathrm{y})$} \\
\hline$<2$ & 47 & 36 \\
\hline $2-10$ & 294 & 206 \\
\hline$>10$ & 51 & 31 \\
\hline \multicolumn{3}{|l|}{ Age at late effects study (y) } \\
\hline $6-10$ & $27^{*}$ & 23 \\
\hline $11-18$ & $250^{*}$ & 192 \\
\hline $19-29$ & $115^{*}$ & 58 \\
\hline \multicolumn{3}{|l|}{$\begin{array}{l}\text { Years after cessation of } \\
\text { therapy }\end{array}$} \\
\hline $5-9$ & 66 & 45 \\
\hline $10-14$ & 326 & 228 \\
\hline
\end{tabular}

* At December 31, 1989. 


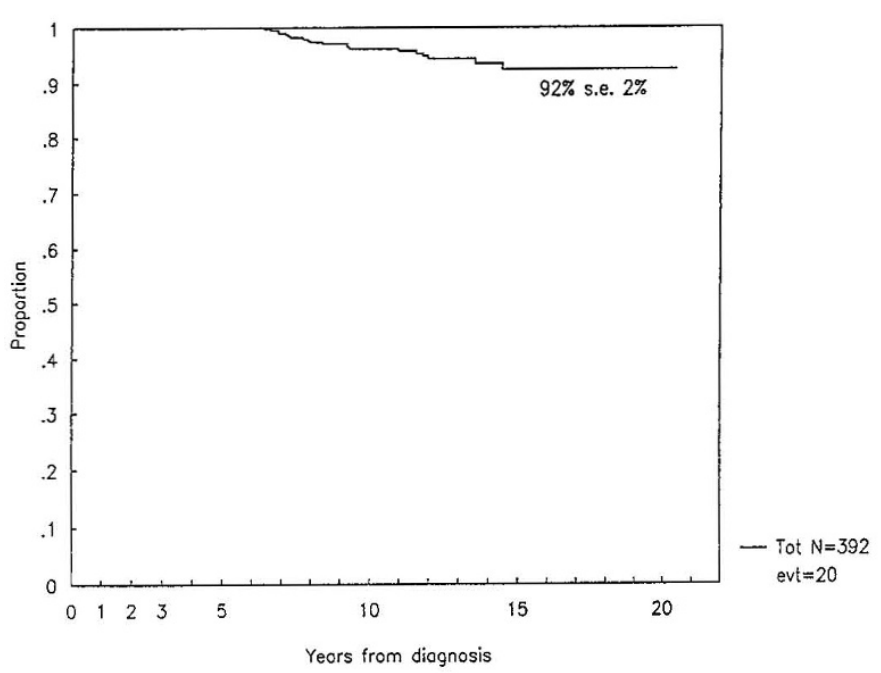

Figure 1. Event-free survival of 392 ex-patients with childhood acute leukemia in first continuous complete remission for $\geq 6 \mathrm{y}$.

Table 2. Late events in 392 ex-patients with childhood acute leukemia (diagnosis 1972-1982)

\begin{tabular}{|c|c|c|c|}
\hline Relapses & Patients & $\begin{array}{l}\text { Years after } \\
\text { diagnosis }\end{array}$ & \\
\hline Bone marrow & 3 & $7,7,7$ & \\
\hline CNS & 3 & $7,8,11$ & \\
\hline Testis & 1 & 8 & \\
\hline Bone marrow $+\mathrm{CNS}$ & 1 & 8 & \\
\hline Second tumors & Patients & $\begin{array}{l}\text { Years after } \\
\text { diagnosis }\end{array}$ & $\begin{array}{c}\text { In area of cranial } \\
\text { irradiation }\end{array}$ \\
\hline \multicolumn{4}{|l|}{ Malignant } \\
\hline Astrocytoma & 2 & 8,12 & Yes \\
\hline Basocellular carcinoma & 3 & $7,7,12$ & Yes \\
\hline M. Hodgkin & 1 & 7 & Not relevant \\
\hline Non-Hodgkin lymphoma & 1 & 12 & Not relevant \\
\hline ANLL & 1 & 15 & Not relevant \\
\hline MDS & 1 & 9 & Not relevant \\
\hline \multicolumn{4}{|l|}{ Benign } \\
\hline Ovarian cyst & 1 & 11 & No \\
\hline Angioleiomyoma & 1 & 3 & No \\
\hline Multinodular struma & 1 & 13 & No \\
\hline Bilateral meningioma & 1 & 20 & Yes \\
\hline Death in CR & Patients & $\begin{array}{l}\text { Years after } \\
\text { diagnosis }\end{array}$ & \\
\hline Preexistent hepatitis & 1 & 13 & \\
\hline Infection & 1 & 6 & \\
\hline Traffic accident & 1 & 9 & \\
\hline
\end{tabular}

\section{Late Side Effects}

Growth. For each patient the height SDS was calculated, defined as the patients' height minus the mean for the pertaining age and sex, divided by the SD for that age. At diagnosis the mean height SDS of the patients was normal. However, $\geq 4$ $y$ after treatment the mean height SDS of both boys and girls was $1 \mathrm{SD}$ lower than for the Dutch population.

The height of the ex-patients was within the normal range of the Dutch population; however, height and weight curves showed a considerable number of ex-patients who were overweight (Fig. 2, $A$ and $B$ ). Both for male and female ex-patients
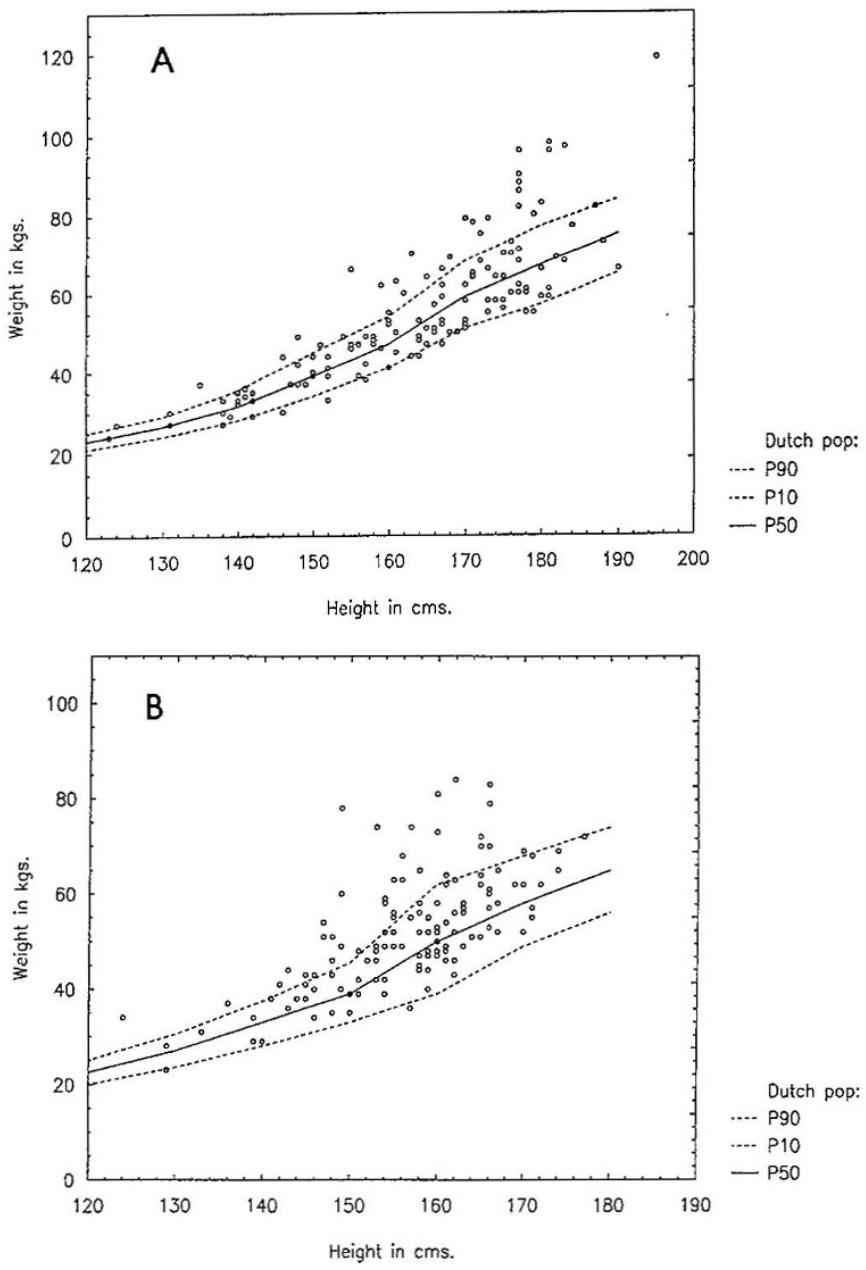

Figure 2. (A) Height and weight in 136 male patients with childhood acute leukemia in first continuous complete remission for $\geq 6 \mathrm{y}$. $(B)$ Height and weight in 137 female patients with childhood acute leukemia in first continuous complete remission for $\geq 6 \mathrm{y}$; pop = population.

the final height was below the median height of the Dutch population: $173 \mathrm{~cm}$ versus 182 for male patients, 163 versus 169 for female patients.

Pubertal development; progeny. Pubertal development started in due time in boys and girls, but progression was slower than in the average Dutch population in ex-patients known to be in the range of development $P$ (pubic hair), $G$ (genital development), or M (breast development) 2-5 (Table 3 ). The median age of the menarche in ex-patients, 12 y (range 10-14 y), was younger than in the average Dutch population: 13 y (range 11-14 y) (11).

Nine infants were born: eight to female ex-patients, and one male ex-patient fathered a child. All babies were well and healthy.

Organ toxicity. Organ toxicity was most frequently reported for the CNS and the skin (Table 4). Late cardiovascular, pulmonary, urogenital, gastrointestinal, hepatic, and musculoskeletal toxicity was rarely reported. The overall immunity, as measured by the incidence of severe infections, seems to be normal in leukemia patients off therapy.

Psychosocial development. A considerable part of the expatients $(51 \%)$ had experienced learning problems. In the 
Table 3. Pubertal development in ex-patients with childhood acute leukemia

\begin{tabular}{|c|c|c|c|c|c|}
\hline & \multicolumn{2}{|c|}{ Dutch population } & \multicolumn{3}{|c|}{ Ex-patients } \\
\hline & P50 (y) & (P10-P90) & $(n)$ & P50 (y) & (P10-P90) \\
\hline \multicolumn{6}{|l|}{ Boys } \\
\hline \multicolumn{6}{|l|}{ Pubic hair } \\
\hline P 2 & 11.7 & $(9-13.5)$ & 11 & 12.5 & $(11.6-15.2)$ \\
\hline P 3 & 13.1 & $(11.7-14.5)$ & 17 & 14.6 & $(13.2-15.9)$ \\
\hline P 4 & 13.9 & $(12.9-15.5)$ & 16 & 16.7 & $(14.1-19.2)$ \\
\hline P 5 & 15.0 & $(13.5-18.4)$ & 38 & 19.1 & (15.7-23.9) \\
\hline \multicolumn{6}{|c|}{ Genital development } \\
\hline G 2 & 11.3 & $(9.3-13.3)$ & 15 & 12.9 & $(11.6-15.2)$ \\
\hline G 3 & 13.1 & $(11.6-14.5)$ & 13 & 14.4 & $(13.2-15.9)$ \\
\hline G 4 & 14.0 & $(12.8-15.6)$ & 20 & 17.4 & $(14.4-21.5)$ \\
\hline G 5 & 15.3 & $(13.5-18.6)$ & 43 & 18.6 & $(15.2-23.1)$ \\
\hline \multicolumn{6}{|l|}{ Girls } \\
\hline \multicolumn{6}{|l|}{ Pubic hair } \\
\hline P 2 & 10.8 & $(9.0-12.6)$ & 12 & 11.3 & $(10.3-13.0)$ \\
\hline P 3 & 11.7 & $(10.2-13.1)$ & 20 & 12.7 & $(11.3-17.2)$ \\
\hline P 4 & 12.6 & $(11.3-14.0)$ & 37 & 16.8 & $(12.1-20.5)$ \\
\hline P 5 & 14.0 & $(12.2-16.4)$ & 45 & 17.3 & (13.9-25.1) \\
\hline \multicolumn{6}{|c|}{ Breast development } \\
\hline M 2 & 10.5 & $(9.1-12.3)$ & 12 & 11.8 & $(10.5-12.9)$ \\
\hline M 3 & 11.7 & $(10.2-13.1)$ & 22 & 12.7 & $(11.3-18.0)$ \\
\hline M 4 & 12.9 & $(11.4-14.5)$ & 33 & 16.8 & $(12.0-20.3)$ \\
\hline M 5 & 14.2 & $(12.5-)$ & 51 & 17.2 & $(13.9-24.8)$ \\
\hline Menarche & 13.3 & $(11.7-14.9)$ & 107 & 12 & $(10-14)$ \\
\hline
\end{tabular}

questionnaire the highest level of education thus far achieved had to be reported. Although many ex-patients were still too young to have reached their final educational level, it was apparent that a large proportion of ex-patients (12\%) was unable to follow normal elementary or secondary school and had to be referred to special schools for children with learning defects. In the average Dutch population only $4 \%$ of the children have to be referred (12). There was a significant correlation between CNS irradiation at younger age and the occurrence of school problems $\left(\chi^{2} p=0.002\right)$.

Fifty-five ex-patients had terminated their education and training, 27 of these had a full-time job, 13 a parttime job, and 5 were unemployed. Five ex-patients were housewives with children. Of five ex-patients the occupational status was not reported.

Medical examinations and insurances. Twenty-nine (52\%) out of 55 medically examined ex-patients were rejected as unfit; 26 men for entry into military service, one woman for nurses training because of short stature, and two ex-patient for reasons unknown.

Five (3\%) out of 171 ex-patients who applied for an insurance, were refused: two for health insurance, two for funeral insurance, and one for an unspecified insurance.

\section{DISCUSSION}

In this study 20 of 392 acute leukemia patients, considered to be cured, suffered from a life-threatening event. The rate of late relapses in this nationwide, multi-institutional study is slightly higher than observed in the single institution studies of St. Jude Children's Research Hospital in the same era (2). The rate of second malignancies is in the same range as the estimated cumulative proportion of $2.53 \%, 15 \mathrm{y}$ after diagno-
Table 4. Late side effects in 273 ex-patients with childhood acute leukemia (diagnosis 1972-1982)

\begin{tabular}{|c|c|}
\hline & Ex-patients \\
\hline \multicolumn{2}{|l|}{ Central nervous system } \\
\hline Learning disabilities & 129 \\
\hline Mental retardation & 4 \\
\hline Epilepsy & $4(52 \%)$ \\
\hline Growth hormone deficiency & 5 \\
\hline \multicolumn{2}{|l|}{ Skin/hair } \\
\hline Thin hair/alopecia & $28(10 \%)$ \\
\hline Melanocytic nevi (moles) & $13(4.7 \%)$ \\
\hline Dysplastic nevi & 2 \\
\hline Vitiligo & 1 \\
\hline Peripheral nervous system & 4 \\
\hline \multicolumn{2}{|l|}{ Skeleton/teeth } \\
\hline Osteoporosis & 3 \\
\hline M. Osgood Schlatter & 2 \\
\hline Dental root anomalies & 2 \\
\hline Dental caries & 6 \\
\hline \multicolumn{2}{|l|}{ Eyes } \\
\hline Loss of vision & 3 \\
\hline Iridocyclitis* & 2 \\
\hline \multicolumn{2}{|l|}{ Ears } \\
\hline Deafness & 3 \\
\hline \multicolumn{2}{|l|}{ Hematological } \\
\hline Thrombocytopenia & 3 \\
\hline Anemia & 1 \\
\hline Liver & 1 \\
\hline Kidneys & 1 \\
\hline Gastrointestinal tract & 1 \\
\hline \multicolumn{2}{|l|}{ Severe infections } \\
\hline Meningitis & 1 \\
\hline Recurrent otitis media & 5 \\
\hline Heart & - \\
\hline Lungs & - \\
\hline Accidents & 13 \\
\hline
\end{tabular}

* After herpes infection during treatment.

sis, reported by the Children's Cancer Study Group, representing a 7-fold excess of all cancers. In the Children's Cancer Study Group study, 24 (56\%) out of 43 second malignancies occurred in the CNS, all in children who had been treated with cranial irradiation; however, no basocellular carcinomas were mentioned (13).

Therapy-related MDS and acute myeloid leukemia have been described in children in relation to previous treatment for solid tumors or acute lymphoblastic leukemia with drugs reacting either directly at DNA, such as the alkylating agents, or indirectly by targeting at DNA-topoisomerase II, such as the epipodophyllotoxins, anthracyclines, and actinomycin D. These second malignancies were associated with characteristic abnormalities of chromosomes 5 and/or 7 after alkylating agents, and of chromosome 11q23 after DNA topoisomerase II targeting drugs (14-16). In this survey two cases of secondary MDS and ANNL were identified. Both patients had been treated with doxorubicin.

The data collected by the questionnaire do not suggest an increase in the incidence of cardiovascular, pulmonary, urogenital, or gastrointestinal tract diseases, or an increased vulnerability of the musculoskeletal system. The overall immunity, as measured by the incidence of severe infections, is normal in ex-patients. No diabetes mellitus has been observed. 
Organ toxicity was most outspoken in the CNS. Although effective in preventing CNS relapse, it has become increasingly clear that cranial irradiation may cause neurotoxicity leading to severe learning disabilities (17). This was also observed in this study, as well as the fact that younger age at cranial irradiation is associated with more school and learning defects (18). These school problems are largely caused by verbal and attention deficits $(19,20)$. A recent study has shown an on-going decline in full-scale intelligence quotient after 18-24 Gy irradiation with the length of time from diagnosis (21).

Short stature in ex-leukemia patients may be caused by a combination of factors, such as growth hormone deficiency and the development of precocious puberty after cranial irradiation, and the longstanding administration of corticosteroids $(22,23)$. In a recent study, disproportionate short stature was established suggesting also a direct effect of chemotherapy on the spinal cartilage growth plates (24).

The occurrence of obesity in a high number of patients is still unexplained. Partial growth hormone deficiency by cranial irradiation, little exercise, high caloric intake, metabolic changes by long-term corticosteroid administration, or a change in body composition (25) may all be factors that play a role, but this phenomenon still needs further investigation.

Cranial irradiation has been related to precocious puberty. However, in our study, the median ages of the consecutive pubertal stages were higher than for the average Dutch population, indicating a delay in pubertal development, notwithstanding early menarche in some girls. This may be associated with gonadal toxicity of the administered chemotherapy (26). In a British study, testicular function after treatment for ALL, including cranial irradiation, was assessed by wedge biopsy at cessation of therapy and subsequently by clinical and biochemical examination, and if possible semen analysis, $10 \mathrm{y}$ later. At cessation of therapy moderate to severe testicular damage was found in the majority of the boys; $10 \mathrm{y}$ later testicular function had recovered completely in all but half of a small number of patients with severe damage at cessation of therapy, indicating that in general the outlook for male fertility in ex-leukemia patients may be considered as good (27). The same investigators assessed that the long-term outlook for ovarian function in girls, treated with chemotherapy without cyclophosphamide or spinal or abdominal irradiation, was also good for most of the patients (28). However, these studies need further confirmation.

The offspring of the ex-patients in the current study is normal. No increase in the incidence of congenital malformations or malignancies in children from ex-leukemia patients has been reported thus far $(29,30)$.

The administration of anthracyclines has been associated with cardiomyopathy in a dose-related fashion (cumulative dose: $>300 \mathrm{mg} / \mathrm{m}^{2}$ ) (31). It is of interest that in this study no clinical signs of cardiomyopathy were reported in 73 ALL patients treated with daunorubicin (cumulative dose $100 \mathrm{mg}$ / $\mathrm{m}^{2}$ ) during induction treatment in study ALL V (7). This phase III study on the effectiveness of daunorubicin also offers an unique opportunity to study any late cardiac effects of low dose anthracycline in a comparative way. Such a study is now underway.
It has been shown that cytostatic treatment is associated with an increase in melanocytic nevi (moles), a strong risk factor for melanoma, in long term cancer survivors (32). However, thus far no increase in the incidence of melanoma in long term cancer survivors has been reported (33).

Shortening of dental roots has been observed after the administration of combination chemotherapy to young children (34). Preliminary study results suggest a relation with certain cytostatic drugs, rather than age at diagnosis for the development of these abnormalities (35).

This survey confirms the data in the literature that prophylactic cranial irradiation is a very important factor for the long-term impairment of the quality of life of children successfully treated for leukemia (17-21). In The Netherlands, since 1984, prophylactic cranial irradiation has effectively been substituted by intensive systemic and intrathecal chemotherapy. Furthermore, it was shown in the ALL VI study that excellent results can be achieved in 70\% of ALL patients without the administration of alkylating agents or anthracyclins (36).

This survey also confirms that the majority of leukemia patients in CCR $4 \mathrm{y}$ after cessation of therapy has been cured; with current more effective treatment strategies the final cure rate may still further improve. Children cured of leukemia should have the same opportunities for education, employment, and insurances as their contemporaries who never had leukemia.

It is wrong to consider cured individuals as patients still suffering with the disease and to reject them for this reason to enter the uniformed services. Job and insurance discrimination in leukemia survivors should be prohibited by law, as for example has been realized in the United States by the passage of the Americans With Disabilities Act (37).

However, because many of the long-term effects of treatment are still unknown, the importance of long-term follow-up of survivors of leukemia has to be stressed. The recommendations of the American Cancer Society Workshop on Adolescents and Young Adults with Cancer (38-41) could be adapted to national or local circumstances.

\section{REFERENCES}

1. George SL, Aur RJA, Mauer AM, Simone JV 1979 A reappraisal of the results of stopping therapy in childhood leukemia. N Engl J Med 300:269-273

2. Rivera GK, Pinkel D, Simone JV, Hancock ML, Crist WM 1993 Treatment of acute lymphoblastic leukemia-30 years' experience at St. Jude Children's Research Hospital. N Engl J Med 329:1289-1295

3. Creutzig U, Ritter J, Schellong G for the AML-BFM Study Group 1990 Identification of two risk groups in childhood acute myelogenous leukemia after therapy intensification in study AML-BFM-83 as compared with study AML-BFM-78. Blood 75:1932-1940

4. Hählen K, Bökkerink J, Van der Does-van den Berg A, Van Leeuwen EF, Postma A 1994 Six months of intensive chemotherapy for childhood ANLL: preliminary results of the study ANLL 87 of the Dutch Childhood Leukemia Study Group. Haematol Blood Transfus 35:734-737

5. Van der Does-van den Berg A, Hählen K, Colly LP, Vossen JM 1988 Treatment of childhood acute non-lymphocytic leukemia with high dose cytosine arabinoside, 6-thioguanine and doxorubicin without maintenance therapy. Pilot study ANLL-80 of the Dutch Childhood Leukemia Study Group (DCLSG). Pediatr Hematol Oncol 5:93-102

6. Van der Does-van den Berg A 1980 Acute lymphocytic leukemia in children in The Netherlands; results of treatment according to protocol ALL II (DCLSG) and immunological studies after cessation of therapy. Thesis, Leiden

7. Van der Does-van den Berg A, van Wering ER, Suciu S, Solbu G, van't Veer M, Rammeloo JA, De Koning J, Van Zanen GE 1989 Effectiveness of Rubidomycin in induction therapy with vincristine, prednisone and $\mathrm{L}$-asparaginase for standard risk childhood acute lymphoblastic leukemia: results of a Dutch Phase III Study (ALL V). Am J Pediatr Hematol Oncol 11:125-133 
8. Behrendt H, Van Leeuwen EF, Schuwirth C, Verkes R, Hermans J, Van der Does-van den Berg A, Van Wering ER 1989 Bone marrow relapse, occurring as first relapse in children with acute lymphocytic leukemia. Med Pediatr Oncol 18:190-196

9. Van der Does-van den Berg A, De Koning J, Reerink H, De Vries JA, Van Zanen GE 1975 Acute Lymfatische leukemie bij kinderen in Nederland; Onderzoek ALLI, 1972-1973. Stichting Nederlandse Werkgroep Leukemie bij Kinderen (SNWLK). Ned Tijdschr Geneeskd 119: 1445-1451

10. Kaplan EL, Meier P 1985 Non parametric estimation for incomplete observations. J Am Stat Assoc 53:457-81

11. Roede MJ, Van Wieringen JC 1985 Growth diagrams 1980. Netherlands third nation-wide survey. Tijschr Soc Gezondheidszorg 63(suppl):1-33

12. Statistical Year-Book 1993. Centraal Bureau voor de Statistiek 1993 SDU Publishers, The Hague

13. Neglia JP, Meadows AT, Robison LL, Kim TH, Newton WA, Ruymann FB, Sather HN, Hammond GD 1991 Second neoplasms after acute lymphoblastic leukemia in childhood. N Engl J Med 325:1330-1336

14. Pui $\mathrm{CH}$, Behm FG, Raimondi SC, Dodge RK, George SL, Rivera GK, Mirro J, Kalwinsky DK, Dahl GV, Murphy SB, Crist WM, Williams DL 1989 Secondary acute myeloid leukemia in children treated for acute lymphoid leukemia. $\mathrm{N}$ Engl J Med 321:136-142

15. Pui CH, Hancock ML, Raimondi SC, Head DR, Thompson E, Wilimas J, Kun LE Bowman LC, Crist WM, Pratt CB 1990 Myeloid neoplasia in children treated for solid tumours. Lancet 336:417-421

16. Rubin CM, Arthur DC, Woods WG, Lange BJ, Nowell PC, Rowley JD, Nachman J, Bostrom B, Baum ES, Suarez CR, Shah NR, Morgan E, Maurer HS, McKenzie SE, Larson RA, Le Beau M 1991 Therapy-related myelodysplastic syndrome and acute myeloid leukemia in children: correlation between chromosomal abnormalities and prior therapy. Blood 78:2982-2988

17. Moss HA, Nannis ED, Poplack DG 1981 The effects of prophylactic treatment of the central nervous system on the intellectual functioning of children with acute lymphoblastic leukemia. Am J Med 71:47-52

18. Jannoun L 1983 Are cognitive and educational development affected by age at which prophylactic therapy is given in acute lymphoblastic leukemia. Arch Dis Child 58:953-958

19. Brouwers P, Poplack DG 1990 Memory and learning sequelae in long-term survivors of acute lymphoblastic leukemia: association with attention deficit. J Pediatr Hematol Oncol 12:174-181

20. Anderson V, Schmibert E, Ekert H, Godber T 1994 Intellectual, educational, and behavioural sequelae after cranial irradiation and chemotherapy. Arch Dis Child 70:476-483

21. Jankovic M, Brouwers P, Valsecchi MG, Van Veldhuizen A, Huisman J, Kamphuis R, Kingma A, Mor W, Van Dongen-Melman J, Ferronato L, Mancini MA, Spinetta J, Masera G for ISPACC 1994 Association of $1800 \mathrm{cGy}$ cranial irradiation with intellectual function in children with acute lymphoblastic leukaemia. Lancet 344:224-227

22. Schriock, EA, Schell MJ, Carter M, Hustu O, Ochs JJ 1991 Abnormal growth patterns and adult short stature in 115 long-term survivors of childhood leukemia. $\mathrm{J}$ Clin Oncol 9:400-405

23. Clayton PE, Shalet SM, Morris-Jones PH, Price DA 1988 Growth in children treated for acute lymphoblastic leukaemia. Lancet 1:460-462

24. Davies HA, Didcock E, Didi M, Ogilvy-Stuart A, Wales JKH, Shalet SM 1994 Disproportionate short stature after cranial irradiation and combination chemotherapy for leukaemia. Arch Dis Child 70:472-475
25. Armbrust W, Tamminga RYJ, Kamps WA 1994 Body composition after treatment for acute lymphoblastic leukemia (ALL). Med Pediatr Oncol 23:274(abstr)

26. Siris ES, Leventhal BG, Vaitukaitis JL 1976 Effects of childhood leukemia and chemotherapy on puberty and reproductive function in girls. N Engl J Med 294:11431146

27. Wallace WHB, Shalet SM, Lendon M, Morris-Jones PH 1991 Male fertility in long-term survivors of childhood acute lymphoblastic leukaemia. Int $\mathrm{J}$ Androl $14: 312-319$

28. Wallace WHB, Shalet SM, Tetlow LJ, Morris-Jones PH 1993 Ovarian function following the treatment of childhood acute lymphoblastic leukaemia. Med Pediatr Oncol 21:333-339

29. Green D, Zevon MA, Lowrie GL, Seigelstein N, Hall B 1991 Congenital anomalies in children of patients who received chemotherapy for cancer in childhood and adolescence. N Engl J Med 325:141-146

30. Hawkins MM, Draper GJ, Smith RA 1989 Cancer among 1348 offspring of survivors of childhood cancer. Int J Cancer 43:975-978

31. Lipshultz SE, Colan SD, Gelber RD, Perez-Atayde AR, Sallan SE, Sanders SP 1991 Late cardiac effects of doxorubicin therapy for acute lymphoblastic leukemia in childhood. N Engl J Med 324:808-815

32. De Wit PEJ, de Vaan GAM, de Boo TM, Lemmens WAJG, Rampen FHJ 1990 Prevalence of naevocytic naevi after chemotherapy for childhood cancer. Med Pediatr Oncol 18:336-338

33. Green A, Smith P, McWhirter W, O'Regan P, Battistutta D, Yarker ME, Lape K 1993 Melanocytic naevi and melanoma in survivors of childhood cancers. $\mathrm{Br} \mathrm{J}$ Cancer 67:1053-1057

34. Rosenberg SW, Kolodney H, Wong GY, Murphy ML 1987 Altered dental roo development in long term survivors of pediatric acute lymphoblastic leukemia. Cancer 59:1640-1648

35. Etty EJ, Van Oort RP, Hogendorf MA, Lyaruu DM, Wöltgens JHM 1994 Late effects of chemotherapy on tooth development in children with acute lymphoblastic leukemie. Med Pediatr Oncol 23:244(abstr)

36. Veerman AJP, Hählen K, Kamps WA, Van Leewwen EF, De Vaan GAM, Van Wering ER, Van der Does-Van den Berg, Solbu G, Suciu G 1990 Dutch Childhood Leukemia Study Group: Early results of Study ALL VI (1984-1988). Haematol Blood Transfus 33: 473-477

37. Hoffman B 1992 Legal remedies to job and insurance discrimination against forme childhood cancer patients. In: Green DM, D'Angio G (eds) Late Effects of Treatment for Childhood Cancer. Wiley Liss, New York, pp 165-170

38. Bleyer WA, Smith RA, Green DM, DeLaat CA, Lampkin BC, Coltman CA, Brady AM, Simon M, Krischer JP, Menck H 1993 Workgroup \#1: long-term care and lifetime follow-up. Cancer 71:2413

39. McKenna RJ, Black B, Hughes R, Listerman JC, Powers Monaco G, Thaler-De Mers DK, Gibson M, Card I, Hays DM 1993 Workgroup \#2: insurance and employability. Cancer 71:2414-2418

40. Baker LH, Jones J, Stovall A, Zeltzer LK, Heiney SP, Sensenbrenner L, Tebbi CK Spoerl EJ, Zook D 1993 Workgroup \#3: psychosocial and emotional issues and specialized support groups and compliance issues. Cancer 71:2419-2422

41. Hammond DG, Nixon DW, Nachman JB, Murphy SB, Ho RCS, Smith MA, Reaman G, Bernstein L, Krailo M, Young JL 1993 Workgroup \#4: clinical research implications. Cancer 71:2423 